\title{
Effects of alternate reef states on coral reef fish habitat associations
}

\author{
David Lecchini • Laure Carassou • \\ Bruno Frédérich • Yohei Nakamura • \\ Suzanne C. Mills • René Galzin
}

Received: 14 April 2011 /Accepted: 27 October 2011 / Published online: 9 November 2011

(C) Springer Science+Business Media B.V. 2011

\begin{abstract}
The present study describes ontogenetic shifts in habitat use for 15 species of coral reef fish at Rangiroa Atoll, French Polynesia. The distribution of fish in different habitats at three ontogenetic stages (new settler, juvenile, and adult) was investigated in coraldominated and algal-dominated sites at two reefs (fringing reef and inner reef of motu). Three main ontogenetic patterns in habitat use were identified: (1) species that did not change habitats between new settler and juvenile life stages ( $60 \%$ of species) or between juvenile and adult stages (55\% of species - no ontogenetic shift); (2) species that changed habitats at different ontogenetic stages (for the transition "new settler to
\end{abstract}

D. Lecchini $(\bowtie) \cdot$ S. C. Mills $\cdot$ R. Galzin

Laboratoire d'Excellence "CORAIL", USR 3278 CNRS-

EPHE, CRIOBE,

98729 Moorea, French Polynesia

e-mail: lecchini@univ-perp.fr

D. Lecchini $\cdot$ L. Carassou

Centre IRD Nouméa, Institut de Recherche pour le

Développement, UR 227,

98848 Noumea, New Caledonia

B. Frédérich

Laboratoire de Morphologie Fonctionnelle et Evolutive, Institut de Chimie, Bât. B6C, Université de Liège,

B-4000 Liège, Belgium

Y. Nakamura

Graduate School of Kuroshio Science, Kochi University, 200 Monobe,

Nankoku, Kochi 783-8502, Japan juvenile stage": $15 \%$ of species; for the transition "juvenile to adult stage": $20 \%$ of species); and (3) species that increased the number of habitats they used over ontogeny (for the transition "new settler to juvenile stage": $25 \%$ of species; for the transition "juvenile to adult stage": $25 \%$ of species). Moreover, the majority of studied species $(53 \%)$ showed a spatial variability in their ontogenetic pattern of habitat use according to alternate reef states (coral reef vs algal reef), suggesting that reef state can influence the dynamics of habitat associations in coral reef fish.

Keywords Habitat selection · Settlement . Rangiroa atoll

\section{Introduction}

Like many marine organisms, coral-reef fish have a bipartite life history, consisting of a pelagic larval stage capable of relatively long-distance dispersal and a relatively sedentary benthic stage (usually juveniles and adults) (Leis and McCormick 2002). The transition from pelagic to benthic habitats, during which the relationship between a fish and its environment changes radically, is a critical phase of the life cycle (settlement phase, Kaufman et al. 1992). Marine fish larvae that have led a pelagic life for several weeks must indeed quickly adapt without prior experience to benthic life. Booth (1991), for example, showed that Dascyllus albisella larvae adapted to juvenile-style 
benthic life within $24 \mathrm{~h}$. Models of habitat selection thus predict that initial choices at settlement have a major influence on subsequent patterns of adult abundance among habitats (for review, see Werner and Gilliam 1984; Gillanders et al. 2003).

Initial distribution patterns established at settlement can however be less important if fishes either move after settlement, or are subject to differential mortality related to habitat type, both of which being susceptible to modify the spatial patterns of juveniles and adults (Gillanders et al. 2003). Fish must increase by several orders of magnitude in size as they grow from larvae to adults, and ecological scaling properties limit the size range over which certain habitats are exploitable (Snover 2008). Many coral reef fish therefore undergo one or more ontogenetic habitat shifts as they grow, in order to maximize growth rates while minimizing predation risk (e.g. McCormick and Makey 1997; Dahlgren and Eggleston 2000; Lecchini and Galzin 2005; Lecchini and Tsuchiya 2008; Pratchett et al. 2008).

Most studies reporting ontogenetic variations in habitat use for coral-reef fish were however conducted on a restricted number of species, rarely included more than two life stages, and were never conducted in the context of habitat degradation (Snover 2008). Yet, many reefs in French Polynesia have changed to alternate states (coral to algal dominance) with reefs dominated by algae being considered as degraded (Mumby et al. 2001; Adjeroud et al. 2005). In the present study, we thus aim at distinguishing habitat associations between three life stages, i.e., new settlers, juveniles and adults, for a broad range of coral-reef fish taxa at Rangiroa Atoll, French Polynesia, and by assessing the effect of habitat degradation on the observed patterns. More specifically, the objectives of this study are to (1) describe habitat associations for 15 coral-reef fish species at three ontogenetic stages, and (2) determine if ontogenetic patterns in habitat associations varied as a function of reef degradation state assessed by the dominance of live corals vs. algal turf on the studied sites.

\section{Material and methods}

Study location

The present study was conducted on the north coast of Rangiroa lagoon, French Polynesia (14 $57^{\circ} 48 \mathrm{~S}, 147^{\circ}$
38'79 W). Two distinct morphological reefs were selected: fringing reef (crowns, which are areas along the submerged reef flat without any emergent land) and inner reef flat of motu (emerged coral cays). Two alternate reef states were sampled in each reef: live coral site (live coral percentage cover $>19 \%$ - algal turf percentage cover $<8 \%$ ) and algal site (algal turf percentage cover $>15 \%$ - live coral percentage cover $<5 \%$ ). Estimates of habitat cover were carried out from six replicate $50 \mathrm{~m}$ belt transects in each site by Line Intersect Transect Method (different habitat categories: algal turf, sand, coral rubble, beach-rock, dead coral and live coral).

\section{Fish sampling}

Diurnal underwater visual censuses of fish were carried out along $2 \mathrm{~m}$ wide transects of $55 \mathrm{~m}$ length for the fringing reef and of $90 \mathrm{~m}$ length for the motu. Sixteen permanent transects were installed at the fringing reef ( 8 transects each at the coral and algal sites; total area surveyed for each site $=880 \mathrm{~m}^{2}$ ) and 10 permanent transects installed at the motu (5 transects each at the coral and algal sites; total area surveyed for each site $=900 \mathrm{~m}^{2}$ ). Fishes were censused during two passes over each transect. On the first pass, the diver swam quickly $\left(>15 \mathrm{mmin}^{-1}\right)$ to record transient fishes that fled from the divers progressing along the transect. On the second pass, the diver swam slowly $\left(<5 \mathrm{mmin}^{-1}\right)$ recording more sedentary species (Harmelin-Vivien et al. 1985). Fish were recorded from all 26 permanent transects in July 2007, October 2007, February 2008 and May 2008. Transects were split up over 2 days for each month (the day of the new moon and the day after). The observer was the same individual throughout the whole experiment.

Fish were identified to species level and ontogenetic stage (new settler, juvenile and adult). New settlers (aged $<1$ week post-settlement) still displayed colour patterns of oceanic larvae (Lecchini et al. 2004; Lecchini 2005; McDermott and Shima 2006). Juveniles (aged from 1 week to 6 months postsettlement) and reproductive adults (aged approx. 6 months) were distinguished based on colour patterns and size criteria described in Lecchini and Galzin (2005). The density of each species at each ontogenetic stage were recorded along each transect. Moreover, the habitat where fish lived was recorded: 
algal turf, sand, coral rubble, beach-rock, dead coral, and live coral. However, when fish was just swimming across transect (especially for transient fish at adult stage), the habitat on which fish lived could not be identified in that case.

\section{Data analysis}

Among the 113 species recorded in total, only those which were observed for at least two ontogenetic stages at each sampling period were retained for the analyses. This resulted in a total of 15 species to be analyzed. Density data were $\log (\mathrm{x}+1)$ transformed in order to reduce the effect of dominant species. Faunistic data were organized with densities for species-ontogenetic stage combinations in columns and the different transects in rows for each reef state (coral or algal site). Habitat data were organized with each habitat characteristic ( $\%$ of algal turf, sand, coral rubble, beach-rock, dead coral, and live coral) in columns and the different transects in rows.

The relationships between fish densities at different life stages and habitat variables were assessed using Co-Inertia analysis (COIA, Dray et al. 2003). COIA is a multivariate method which provides great flexibility in identifying the common structure in a pair of data tables. COIA aims to find a vector in the environmental space and a vector in the faunistic space with maximal co-inertia between them. These two vectors thus define the new ordination plan on which environmental and faunistic variables are separately projected and compared. The COIA was based on the matching between the coordinates of habitat variables on a normed PCA and of fish densities on a centered PCA (Dray et al. 2003). A Monte-Carlo test with 10 000 permutations was used to confirm the significance of the COIA results (fixed-D test). The degree of agreement between habitat and fish variables was assessed using total inertia and RV coefficient, which both increase with the strength of the relationship between the two data sets (Dray et al. 2003). Two coinertia analyses were conducted, one on data from coral-dominated sites, and one on data from algaldominated sites, allowing the comparisons of fish ontogenetic patterns in habitat use between the two reef states. COIA analyses were performed using the ADE-4 software. Species-specific examples were then used to highlight the variability of ontogenetic patterns according to alternate reef states (coral vs. algal sites) revealed by COIA.

\section{Results}

A total of 1408 new settlers belonging to 31 species, 4318 juveniles belonging to 58 species, and 13986 adults belonging to 113 species were recorded at Rangiroa. Among these, 15 species were collected for at least two life stages, corresponding to a total of 1073 new settlers, 3018 juveniles and 6609 adult fish included in the analyses.

Habitat associations of coral reef fish according to life stages

The co-structure between habitat and fish variables was significant in the two sites (Monte-Carlo tests, $P<0.001$ in both cases). The two first axes of COIA helped in visualizing $96.2 \%$ and $81.6 \%$ of this costructure in coral and algal sites, respectively (Fig. 1). However, the degree of agreement between the two data sets was higher in coral-dominated sites than in algal-dominated sites (total inertia $=1.83$ and $0.40, \mathrm{RV}$ coefficient $=0.43$ and 0.15 , respectively; $P<0.001$ in both cases; Fig. 1). The projections of habitat variables (Fig. 1a, c) and fish variables (Fig. 1b, d) on the two first axes of COIA for each reef state allowed identifying those fish species that exhibited (or not) ontogenetic shifts in habitat associations (i.e. when coordinates of fish species were associated to different habitat variables at different life stages). Thus, three ontogenetic patterns in habitat associations were highlighted: (1) some species did not change habitats between new settler and juvenile life stages $(60 \%$ of species) or between juvenile and adult stages (55\% of species - no ontogenetic shift). For example, in both coral and algal sites, Chrysiptera leucopoma settled mainly on dead-coral and algal turf, where they remained abundant at the juvenile and adult stages ("chleu" in Fig. 1b, d). (2) Some species used different habitats either between new settler and juvenile stages (15\% of species) or between juvenile and adult stages (20\% of species) (ontogenetic shift). For example, in both coral and algal sites, new settlers and juveniles of Abudefduf sexfasciatus were abundant in beach-rock, whereas adults preferentially occupied dead coral and algal 

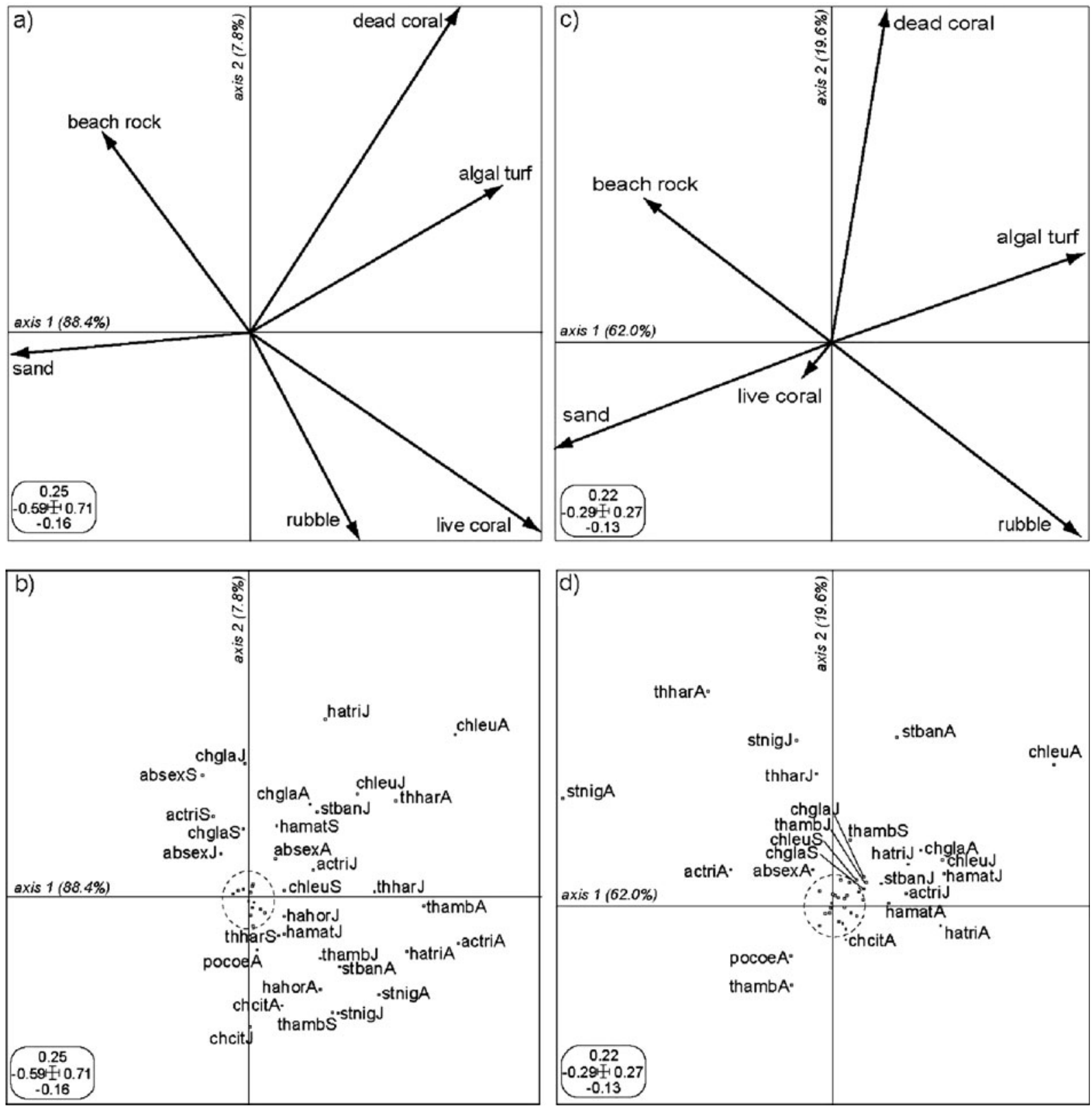

Fig. 1 Co-inertia analysis coupling the $\log (\mathrm{x}+1)$ transformed density of 45 species-life stages combinations and habitat variables in $\mathbf{a}, \mathbf{b}$ coral-dominated and $\mathbf{c}$, $\mathbf{d}$ algal-dominated sites. a-c projection of habitat variables and $\mathbf{b}-\mathbf{d}$ projection of fish species-life stages combinations, on the two first axes of the COIA. Total inertia and RV coefficient of both COIA are given in the result section. Species codes correspond to the two first letters of genus names, followed by the three first letters of species names, as follows: absex: Abudebduf sexfasciatus, actri: Acanthurus triostegus, chcit: Chaetodon citrinellus, chgla: Chrysiptera glauca, chleu: Chrysiptera leucopoma, cogai:

Coris gaimard, govar: Gomphosus varius, hahor: Halichoeres hortulanus, hamat: Halichoeres margaritaceus, hatri: Halichoeres trimaculatus, pocoe: Pomacentrus coelestis, stnig: Stegastes nigricans, stban: Stethojulis bandenensis, thamb: Thalassoma amblycephalum, thhar: Thalassoma hardwicke. Capital letters represent the different life stages, with $\mathrm{A}=$ Adults, $\mathrm{J}=$ Juveniles, $\mathrm{S}=$ new settlers. The labels of speciescombinations contributing to less than $0.5 \%$ of the variability on axes 1 and 2 (within the dashed circle) are not represented for clarity 
turf ("absex" in Fig. 1a, b). Lastly, (3) some species increased the number of habitats used across ontogenetic development $(25 \%$ of species between new settlers vs. juveniles, and $25 \%$ of species between juveniles vs. adults). For example, in both coral and algal sites, the new settlers of Acanthurus triostegus were found almost exclusively on beach-rock, whereas juveniles were found on beach-rock and rubble, and adults on all habitats except sandy bottom ("actri" in Fig. 1a, b).

Variability of ontogenetic patterns

according to alternate reef states

A comparative analysis of ontogenetic patterns showed that eight out of the 15 most abundant species displayed a spatial variation in their habitat associations and/or ontogenetic patterns according to alternate reef state (Table 1). For example, Stegastes nigricans used different habitats and had different ontogenetic patterns on each reef state. In coral site, S. nigricans settled mainly on beach-rock while juveniles and adults lived on beach-rock and live coral (i.e., increased the number of habitats used across ontogenetic development). In algal site, $S$. nigricans settled and remained mainly on dead coral and algal turf throughout all three ontogenetic stages (i.e. no ontogenetic shift). Some other species had the same ontogenetic pattern, but used different habitat associations on each reef state. For example, the new settlers of Thalassoma hardwicke were found almost exclusively on live coral in the coral site and on algal turf in the algal site, whereas juveniles and adults lived on all habitats except sandy bottom on both coral and algal sites (i.e. for both sites, increased the number of habitats used across ontogenetic development). Lastly, seven species did not display a spatial variation in their habitat associations and/or ontogenetic patterns according to alternate reef state (Table 2). Finally, no spatial variability in ontogenetic patterns was detected in the 15 studied species according to the reef type (motu vs. fringing reef).

\section{Discussion}

The present study examined the ontogenetic shifts in habitat associations for a number of coral reef fishes (15 species) in reefs of varying stage of degradation (i.e. coral dominated versus algal dominated). Using direct observations of the presence and abundance of different life stages (new settler, juvenile and adult) on specific habitats (motu and fringing reef) and micro-habitats (algal turf, sand, coral rubble, beachrock, dead coral, and live coral), the results highlighted the shifts that occur in a whole suite of reef fish, throughout their life. Thus, three main ontogenetic patterns in habitat associations were identified, two of which involved habitat shifts: (1) species did not change habitats between new settler and juvenile life stages $(60 \%$ of species) or between juvenile and adult stages (55\% of species - no ontogenetic shift); (2) species that used different habitats between ontogenetic stages; and (3) species that increased the number of habitat types they used through their ontogeny (Fig. 1). In addition, the results demonstrated that the actual habitat associations themselves and how they change with ontogeny could differ with changing reef state. Thus, the comparative analysis of ontogenetic patterns showed that eight out of the 15 most abundant species displayed a spatial variation in their habitat associations and/or ontogenetic patterns according to alternate reef state (Tables 1 and 2). Overall, the notion that reef fish species utilize multiple habitats throughout their life cycle is something that is discussed widely (e.g. McCormick and Makey 1997; Dahlgren and Eggleston 2000; Gillanders et al. 2003; Pratchett et al. 2008), but lacks detailed data to back it up.

Although morphological and ecological characteristics of marine and freshwater fish have previously been reported to be strongly interrelated (Hjelm et al. 2001; McCormick et al. 2002), such studies within an ontogenetic context are rare and have focused on size categories rather than specific physiological and morphological thresholds (Werner and Gilliam 1984; Pinder et al. 2005; Pratchett et al. 2008). For example, Mellin et al. (2007) showed that $39 \%$ of fish species recorded at New Caledonia used different habitats as they grow from juvenile to adult life stages. Nakamura et al. (2009) highlighted two ontogenetic patterns in habitat associations (seagrass bed, coral rubble, branching coral and tabular coral) between new settler and juvenile life stages of coral reef fish at Ishigaki Island (Japan): 1) the new settlers and juveniles had an ubiquitous distribution among the four habitats (Acanthuridae species - no ontogenetic shift); 2) the new settlers distributed in all habitats, 


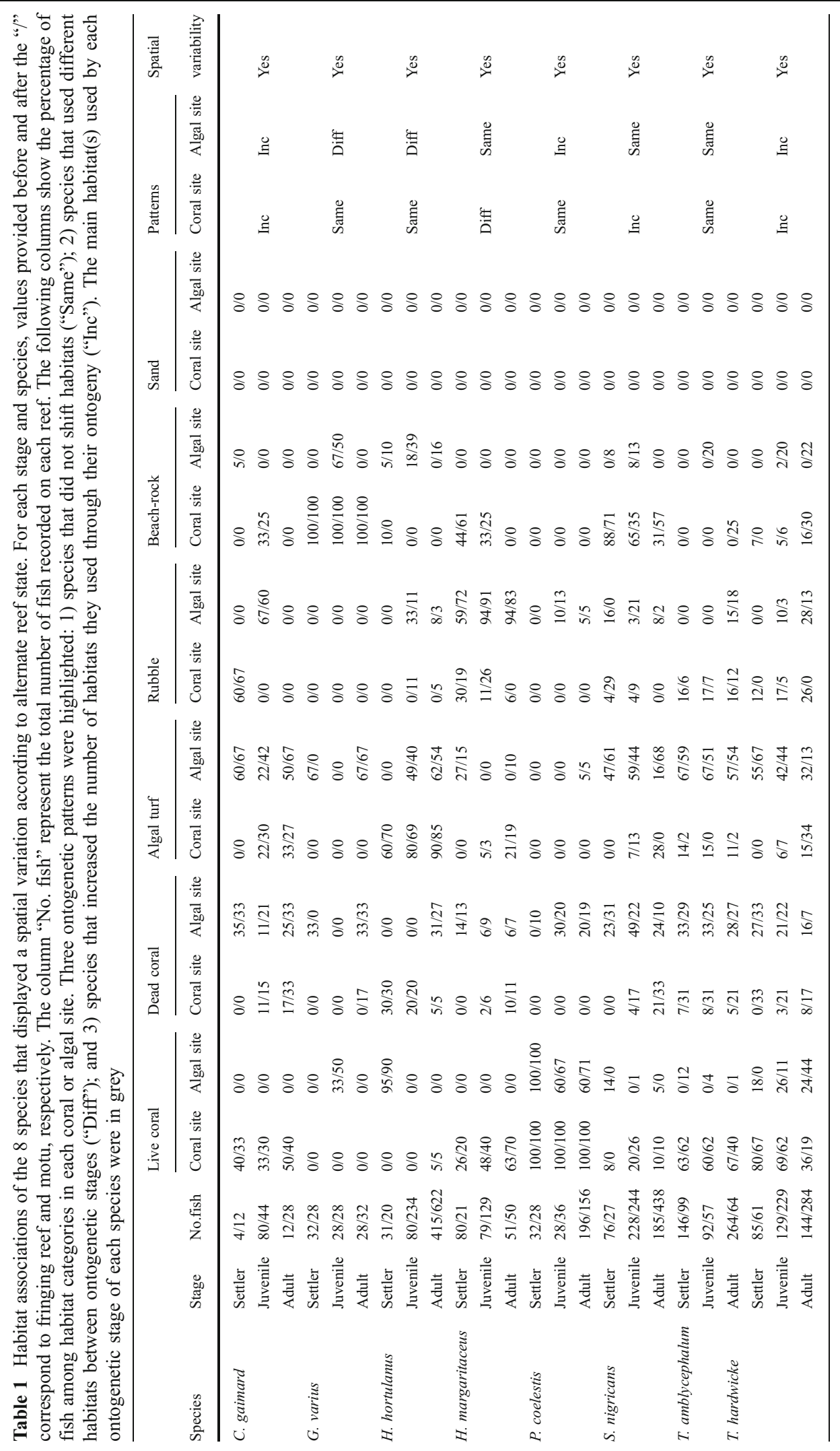




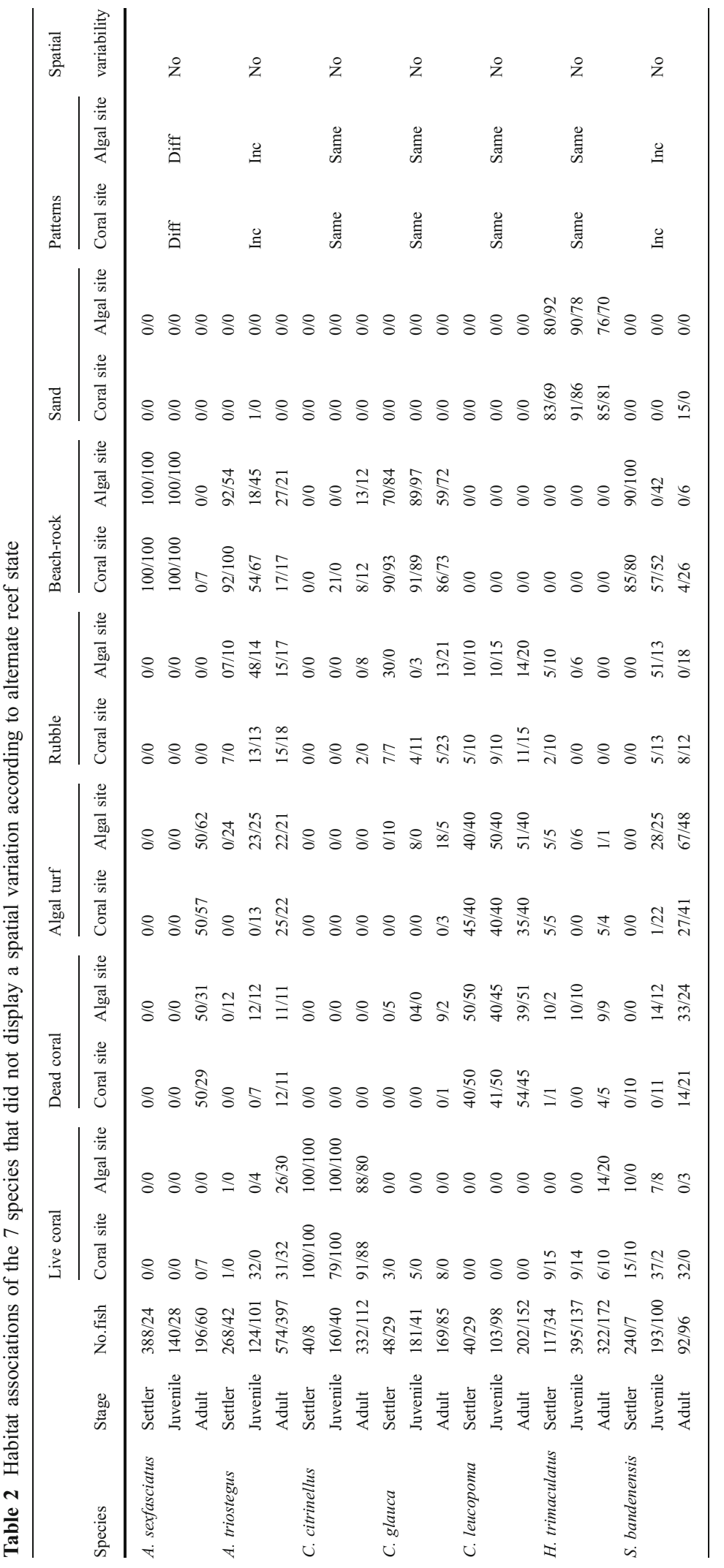


but juveniles restricted to coral habitat (Pomacentridae and Chaetodontidae species). In coral reef, fish species undergo a series of prominent habitat shifts, firstly when propagules are ejected into a pelagic environment, secondly when fully developed pelagic larvae settle back to the juvenile/adult benthic habitat, and lastly at sexual maturity (Leis and McCormick 2002). In our study, habitat shifts were important between juvenile and adult stages (45\% of species). Thus, ontogenetic development from the juvenile to adult life stage is generally marked by a move to sexual maturity (Thresher 1984). Associated with this is any manner of behavioural, territorial and even nesting habitat characteristics and requirements that were formerly not required during the juvenile stage (Thresher 1984). In our study, habitat shifts were also important between new settler and juvenile stages ( $40 \%$ of species). The main morphological changes between the new settler and juvenile stages actually occur within a day or two post-settlement (McCormick et al. 2002). However, some changes that occur at the settler-juvenile transition that refers to a week after settlement (as in the present paper) are likely to be more related to behaviour or food sources (Leis and McCormick 2002). Nevertheless, these mechanisms of observed ontogenetic shifts (sexual maturity, metamorphosis, behaviour or food sources) are highly modified by the spatial variability in environmental conditions (Doherty 2002; Wilson et al. 2010). Indeed, the comparative analysis of ontogenetic patterns highlighted that eight out of the 15 most abundant species displayed a spatial variation in their habitat associations and/or ontogenetic patterns according to alternate reef state (Tables 1 and 2). Because proportion of typical settlement habitat of one species may be different between coral and algal sites, some larvae may have to settle on alternative habitats according to reef status. Several recent studies showed that when reefs change from coral to algal dominated, the fish community changes with decreases in coral dependent species and increases in some herbivores (e.g. Jones et al. 2004; Wilson et al. 2006; McCormick et al. 2010). Pratchett et al. (2008) showed that butterflyfishes with strong reliance on corals appear to be constrained to settle in habitats that provide access to essential prey resources, precluding their use of distinct juvenile habitats. However, what will the future of these species be if reef change from coral to algal dominance? In our study, some species have the abilities to change their preferred settlement habitat according to alternate reef state. For example, the new settlers of Thalassoma amblycephalum and T. hardwicke were found almost exclusively on live coral in the coral site while they settled on algal turf in the algal site (Table 1). However, this change of preferred habitat will be consequences on growth and survival of individuals. Indeed, coral health state influences strongly vulnerability of new settlers to predators, with a higher mortality and weaker growth on algal habitat than live habitat (e.g. Lecchini et al. 2007; McCormick 2009). Therefore, such changes in settlement patterns with reef degradation may lead to a shift in the community structure of reef-associated fish communities (Feary et al. 2007; Pandolfi et al. 2011).

Overall, the present study highlighted the major habitat shifts from new settlers to juveniles $(40 \%$ of species) and from juvenile to adult life stages (45\% of species) by a broad range of fish taxa (15 species) at Rangiroa. However, the majority of studied species (53\%) showed a spatial variability in their ontogenetic pattern of habitat use according to alternate reef states (coral reef vs algal reef), suggesting that reef state can strongly influence the dynamics of habitat associations in coral reef fish. Thus, future studies are still required to better understand the mechanisms of observed ontogenetic shifts. An increased understanding of how the morphological, physiological and environmental processes, as well as their variability, influence the spatial variability in habitat associations of marine organisms may lead to a better management of marine populations.

Acknowledgements Tropical Fish Tahiti, Service de la Perliculture and Service de la Pêche of French Polynesia for kindly agreeing to house this study in their facilities. This research was supported by grants from ANR (ANR-06-JCJC0012-01), MOM (06 PF 15) and CRISP program (Coral Reef Initiative in the South Pacific-C2A).

\section{References}

Adjeroud M, Chancerelle Y, Schrimm M, Perez T, Lecchini D, Galzin R, Salvat B (2005) Detecting the effects of natural disturbances on coral assemblages in French Polynesia: a decade survey at multiple scales. Aqua Liv Res 18:111-123

Booth DJ (1991) The effects of sampling frequency on estimates of recruitment of the domino damselfish Dascyllus albisella (Gill). J Exp Mar Biol Ecol 14:149-159 
Dahlgren CP, Eggleston DB (2000) Ecological processes underlying ontogenetic habitat shifts in a coral reef fish. Ecology 81:2227-2240

Doherty PJ (2002) Variable replenishment and the dynamics of reef fish populations. In: Sale PF (ed) Coral reef fishes: dynamics and diversity in a complex ecosystem. Academic, San Diego, pp 327-358

Dray S, Chessel D, Thioulouse J (2003) Co-inertia analysis and the linking of ecological data tables. Ecology 84:307-339

Feary DA, Almany GR, McCormick MI, Jones GP (2007) Habitat choice, recruitment and the response of coral reef fishes to coral degradation. Oecologia 153:727-737

Gillanders BM, Able KW, Brown JA, Eggleston DB, Sheridan PF (2003) Evidence of connectivity between juvenile and adult habitats for mobile marine fauna: an important component of nurseries. Mar Ecol Prog Ser 247:281-295

Harmelin-Vivien ML, Harmelin JG, Chauvet C, Duval C, Galzin R, Lejeune P, Barnabé G, Blanc F, Chevalier R, Duclerc J, Lasserre G (1985) Evaluation visuelle des peuplements et populations de poissons: Méthodes et problèmes. Terre et Vie, Revue d'Ecologie 40:467-539

Hjelm J, Svanback R, Bystrom P, Persson L, Wahlstrom E (2001) Diet-dependent morphology and ontogenetic reaction norms in Eurasian perch. Oikos 95:311-323

Jones GP, McCormick MI, Srinivasan M, Eagle JV (2004) Coral decline threatens fish biodiversity in marine reserves. Proc Nat Acad Sci 21:8251-8253

Kaufman L, Ebersole J, Beets J, McIvor CC (1992) A key phase in the recruitment dynamics of coral reef fishes: post-settlement transition. Env Biol Fish 34:109-118

Lecchini D, Dufour V, Carleton J, Strand S, Galzin R (2004) Study of the fish larval flux at Moorea Island: is the spatial scale significant? J Fish Biol 65:1142-1146

Lecchini D (2005) Spatial and behavioural patterns of reef habitat settlement by fish larvae. Mar Ecol Prog Ser 301:247-252

Lecchini D, Galzin R (2005) Spatial repartition and ontogenetic shifts in habitat use by coral reef fishes (Moorea, French Polynesia). Mar Biol 147:47-58

Lecchini D, Planes S, Galzin R (2007) The influence of habitat characteristics and conspecifics on attraction and survival of coral reef fish juveniles. J Exp Mar Biol Ecol 341:85-90

Lecchini D, Tsuchiya M (2008) Temporal consistency of ontogenetic shifts in habitat use by coral reef fishes in the northernmost coral ecosystem in the world (Kudaka Island, Japan). J Fish Biol 72:2645-2654

Leis JM, McCormick MI (2002) The biology, behavior, and ecology of the pelagic, larval stage of coral reef fishes. In: Sale PF (ed) Coral reef fishes: dynamics and diversity in a complex ecosystem. Academic, San Diego, pp 171-199
McCormick MI, Makey LJ (1997) Post-settlement transition in coral reef fishes: overlooked complexity in niche shifts. Mar Ecol Prog Ser 153:247-257

McCormick MI, Makey LJ, Dufour V (2002) Comparative study of metamorphosis in tropical reef fishes. Mar Biol 141:841-853

McCormick MI (2009) Behaviourally mediated phenotypic selection in a disturbed coral reef environment. PLoS One 4:e7096

McCormick MI, Moore JAY, Munday PL (2010) Influence of habitat degradation on fish replenishment. Coral Reefs 29:537-546

McDermott CJ, Shima JS (2006) Ontogenetic shifts in microhabitat preference of the temperate reef fish Forsterygion lapillum: implications for population limitation. Mar Ecol Prog Ser 320:259-266

Mellin C, Kulbicki M, Ponton D (2007) Seasonal and ontogenetic patterns of habitat use in coral reef fish juveniles. Estuar Coast Shel Sci 52:1-11

Mumby PJ, Chisholm JRM, Edwards AJ, Clark CD, Andrefouet S, Jaubert J (2001) Unprecedented bleaching-induced mortality in Porites spp. at Rangiroa Atoll, French Polynesia. Mar Biol 139:183-189

Nakamura Y, Shibuno T, Lecchini D, Kawamura T, Watanabe Y (2009) Spatial variability in habitat associations of preand post-settlement stages of coral reef fishes at Ishigaki Island, Japan. Mar Biol 156:2413-2419

Pandolfi JM, Connolly SR, Marshall DJ (2011) Projecting coral reef futures under global warming and ocean acidification. Science 333:418-422

Pinder AC, Gozlan RE, Beyer K, Bass JAB (2005) Ontogenetic induced shifts in the ecology of sunbleak Leucaspius delineatus during early development. J Fish Biol 67:205-217

Pratchett MS, Berumen ML, Marnane MJ, Eagle JV, Pratchett DJ (2008) Habitat associations of juvenile versus adult butterflyfishes. Coral Reefs 27:541-551

Snover ML (2008) Ontogenetic habitat shifts in marine organisms: Influencing factors and the impact of climate variability. Bull Mar Sci 83:53-67

Thresher RE (1984) Reproduction in reef fishes. TFH Publications, Neptune City, NJ, p 399

Werner EE, Gilliam JF (1984) The ontogenetic niche and species interactions in size-structured populations. Ann Rev Ecol Syst 15:393-425

Wilson SK, Graham NAJ, Pratchett MS, Jones GP, Polunin NVC (2006) Multiple disturbances and the global degradation of coral reefs: are reef fishes at risk or resilient? Glob Chang Biol 11:2220-2234

Wilson SK, Depczynski M, Fisher R, Holmes TH, O’Leary RA, Tinkler P (2010) Habitat associations of juvenile fish at Ningaloo Reef, Western Australia: the importance of coral and algae. PLoS One 5:1-7 